\title{
Influence of explosive welding parameters on properties of bimetal Ti-carbon steel
}

\author{
Mariusz Prazmowski ${ }^{*}, 1$, Michat Najwer ${ }^{1}$, Henryk Paul $^{2}$, and Dariusz Andrzejewski ${ }^{1}$ \\ ${ }^{1}$ Opole University of Technology, Faculty of Mechanics, 5 Mikołajczyka St., Opole, Poland \\ ${ }^{2}$ Polish Academy of Science, Institute of Metallurgy and Materials Science, 25 Reymonta St., \\ Cracow, Poland
}

\begin{abstract}
Explosion welding of metals is a process of great technological significance in terms of modern metal composites manufacturing possibilities Nevertheless, selecting welding parameters is not an easy task. This paper assesses the effect of various values of distance of sheets on the quality of the bond zone in titanium (Ti Gr.1) - carbon steel (P355GH) structure. The research was carried out for initial state bonds i.e. immediately following explosion welding. The results of mechanical and structural investigations were presented. In order to determine changes in the value of strengthening, microhardness tests of both the weld and the joined plates were performed. Performed metallographic analysis shows that the standoff distance affects the quality of the bond zone boundary. Smaller distance promotes the formation of waves with lower parameters (of length and height), whereas greater distances allow forming the bond of a more pronounced, repetitive wavy character, however, increasing the quantity of the fusion zone at the same time. Also, the initial distance between the materials to be joined makes for the strengthening in the areas adjacent to bond boundary. The results received allowed to conclude that for the assumed parameters it is possible to obtain Ti -carbon steel bi-metal with properties meeting the standard's requirements.
\end{abstract}

\section{Introduction}

High strength, low density, and excellent corrosion resistance are the main properties that make titanium attractive for a variety of applications. Examples include aircraft (high strength in combination with low density), aero-engines (high strength, low density, and good creep resistance up to about $550^{\circ} \mathrm{C}$ ), biomedical devices (corrosion resistance and high strength), and components in chemical processing equipment (corrosion resistance) [1]. The relatively high cost of titanium has hindered wider use, for example in automotive applications. To minimize the inherent cost problem, successful applications must take advantage of the special features and characteristics of titanium that differentiate it from competing engineering materials. The solution to this problem could be the use of layered materials [2, 3]. It is usually sufficient to apply a thin layer of a material applied on a relatively inexpensive base (construction) material to meet the operation requirements, e.g.

*Corresponding author: m.prazmowski@po.opole.pl 
to obtain element characterized both by high corrosion resistance and strength [4]. However, joining materials with special properties (e.g. in the form of metal sheets) still is a big technological problem. That is why, one increasing interest in the technology of explosive treatment of materials, including the technology of explosive cladding, is observed.

The classic definition of the explosive welding defines the letter as the process of metal joining in the solid state, under the effect of a collision with high velocities caused by a controlled detonation of an explosive charge. Basically, this process can be divided into three general stages: detonation of the explosive charge, deformation and acceleration of the flyer plate and collision of the plates $[5,6]$. The action of the explosive charge deforms and relocates the flyer plate (placed ad a pre-determined distance) in the direction of the base plate (Fig. 1).

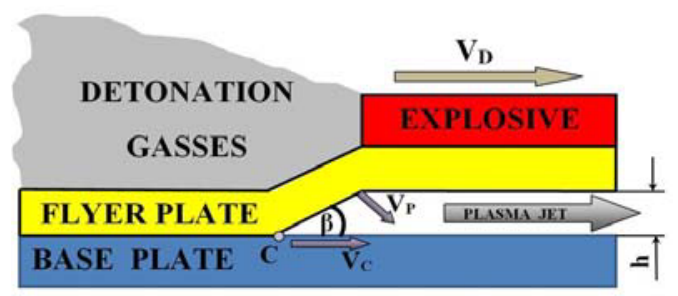

Fig. 1. Scheme of the parallel system and the shape of the ejector die in the welding process. The basic parameters are: $V_{D}$ - detonation velocity, $V_{P}$ - velocity of plate collision, $V_{c}$ - velocity at the collision point, $\beta$ - collision angle, $\mathrm{h}$ - distance between the plates, $\mathrm{C}$ - collision point.

Optimal bonding parameters, affecting equally the quality of the bond and mechanical properties of the resulting clad, must be correctly selected at the stage of designing the blast arrangement. Explosion welding parameters include physical and mechanical properties of the welded materials, the quality and quantity of the explosive, the method of detonation initiation, and the geometry of the welding structure. The event that determines the joining of materials during explosion welding is the collision of the flyer plate with the base plate. Key parameters which are decisive for obtaining a 'proper' bond during explosion welding are the collision point speed $v_{C}$ and the impact angle of sheets $\beta$. They are highly dependent on the detonation velocity of the explosive $v_{D}$ and the stand-off distance between the sheets (so-called bond window) $h[5,9]$. The values of these settings are individually selected for particular combination of metals and alloys on the basis of equations widely available in literature. The stand-off distance is an independent variable which allows obtaining the required conditions of impact and directly influences the value of the impact angle. Literature review $[5,8]$ shows that the main factor deciding about the particular stand-off distance between the plates to be used is the thickness of the flyer plate $(t)$. Usually, this parameter ranges between $0,5 t-4 t$. The appropriate selection of the stand-off distance will ensure obtaining the collision velocity specific for a given system of materials, e.g. [5, 8-9].

The present study focuses on the analysis of the influence of the stand-off distance between the plates on the morphological changes in the bond zone and mechanical properties of the Ti Gr.1/P355GH clad.

\section{Research techniques}

\subsection{Research material}

Research presented in this work was carried out on bimetal plates produced by explosion welding by EXPLOMET High-Energy Techniques Works in Opole. Explosion bonding was performed in a parallel arrangement where the base material was a $25 \mathrm{~mm}$ sheet of 
carbon steel designed for operation in elevated temperatures whereas the deposited material (flyer plate) was a $12 \mathrm{~mm}$ Titanium sheet (Ti Gr.1 alloy). The chemical composition of both materials was shown in Table 1 and 2.

Table 1. The chemical composition of steel sheets, as per the supplier's certificate[10].

\begin{tabular}{|c|c|c|c|c|c|c|c|}
\hline $\begin{array}{c}\text { Basic } \\
\text { Material }\end{array}$ & \multicolumn{7}{|c|}{ Chemical composition (\%) } \\
\hline & $\mathrm{C}$ & $\mathrm{Mn}$ & $\mathrm{Si}$ & $\mathrm{P}$ & $\mathrm{S}$ & $\mathrm{Cr}$ & $\mathrm{Cu}$ \\
\cline { 2 - 9 } & 0.16 & 1.46 & 0.31 & 0.014 & 0.004 & 0.05 & 0.15 \\
\cline { 2 - 8 } P355GH & $\mathrm{Ni}$ & $\mathrm{Mo}$ & $\mathrm{Al}$ & $\mathrm{V}$ & $\mathrm{Nb}$ & $\mathrm{Ti}$ & $\mathrm{Fe}$ \\
\cline { 2 - 8 } & 0.06 & 0.02 & 0.033 & 0.004 & 0.009 & 0.004 & rest \\
\hline
\end{tabular}

Table 2. The chemical composition of titanium sheets, as per the supplier's certificate [11].

\begin{tabular}{|c|c|c|c|c|c|c|}
\hline Basic & \multicolumn{6}{|c|}{ Chemical composition [\%] } \\
\cline { 2 - 7 } Material & $\mathrm{C}$ & $\mathrm{Fe}$ & $\mathrm{N}$ & $\mathrm{O}$ & $\mathrm{H}$ & $\mathrm{Ti}$ \\
\hline Ti Gr.1 & $<0.08$ & $<0.02$ & $<0.03$ & $<0.18$ & $<0.015$ & Rest \\
\hline
\end{tabular}

Bonding was carried out in parallel arrangement as per the diagram shown in Fig. 1, for which a constant detonation velocity $\left(\mathrm{v}_{D}=2000 \mathrm{~m} \cdot \mathrm{s}^{-1}\right)$ and a variable stand-off distance between the plates $\mathrm{h}$ were assumed. The designation of the produced plates with process parameters were shown in Tab. 3.

Table 3. Designation of the produced plates and the relations between process parameters.

\begin{tabular}{|c|c|c|}
\hline Plate & $\begin{array}{c}\text { Detonation velocity } \\
\text { VD }\left[\mathrm{m} \cdot \mathrm{s}^{-1}\right]\end{array}$ & $\begin{array}{c}\text { Stand off distance } \\
\mathrm{h}[\mathrm{mm}]\end{array}$ \\
\hline H10 & \multirow{3}{*}{2000} & 10 \\
\cline { 1 - 1 } H12 & & 12 \\
$\mathrm{H} 15$ & & 15 \\
\hline
\end{tabular}

\subsection{Mechanical properties}

Mechanical properties, based on technological tests of shearing, lateral bending and ram trials were completed according to EN13445-2 standard.

The first trial of the joint interface was a lateral bending test. Flat specimens of $10 \mathrm{x} \mathrm{g}$ $\mathrm{mm}$ cross-section ( $\mathrm{g}$ is the sum of the thickness of the base and deposited material) and the length of $200 \mathrm{~mm}$ sampled perpendicular to the detonation wave propagation were selected for the tests. The specimens were bent by $180^{\circ}$ on a d=40mm diameter rod (Fig. 2a).

Since the bending test may be faulty in many instances due to the wavy nature of the bond, ram test Ro was additionally carried out to evaluate resistance to splitting. The samples of the ram tests were presented in Fig. 2b. The assessment of the joint strength was performed based on shearing test. The specimens were sampled from the clad in such a way that the shearing plane was parallel to the direction of the detonation propagation wave. The shape and dimensions of the specimens were given in Fig. 2c. The shearing and ram trials were performed until the total separation of the material occurred, recording the maximum force needed for the separation to happen. For ram and shearing, the spot of the sample destruction was macroscopically observed. For strong bimetals, the characteristic place of destruction is the area in the deposited or base material (typically the weaker one). The destruction of the specimen at the joint interface indicates poor strength properties of the analysed clad. 


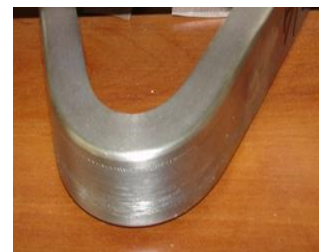

a)

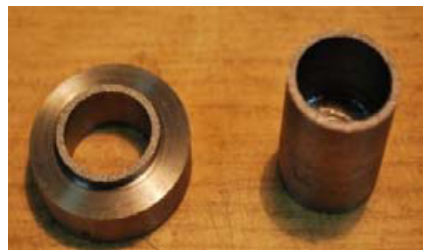

b)

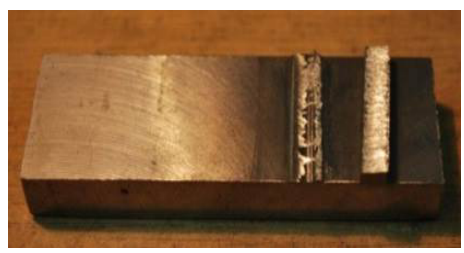

c)

Fig. 2. Shape of the sample for: a) lateral bending test, b) ram test, c) shearing test.

Changes in the strength close to the weld zone, in the longitudinal section of the joined sheets, were analysed by microhardness measurement by Vickers method using LECO MHT Series 200 microhardness tester under the load of $100 \mathrm{~g}$. The measurements were performed along the line perpendicular to the interface ( 3 series). Impresses were made from the joint interface, outside melt regions, locating the first measurement at $0.04 \mathrm{~mm}$ from the bottom of the wave for each of the materials in the bimetal. The results presented in the paper are a mean value of three parallel measurements. The obtained average results for the tested bimetals were compared to the hardness of the input material as shipped (prior welding).

\subsection{Optical microscopy observation}

The material for microscopic examinations was sampled from the fabricated clads as well as from as-delivered sheets. The samples of output material were taken parallel and perpendicular to rolling direction. In the case of clads the polished specimens were produced as sections perpendicular to sheet surface and parallel to the detonation front motion. The analysis of the microstructural changes was conducted using an optical microscope Olympus IX 70 and an image analyzer LECO IA 32. In particular, the measurements of waves parameters were done on carefully polished surfaces using LECO IA 32 image analyzer, including: the length of the bond line $L$, height $(H)$ and wave length $(n)$ as well as the area of the melt surface $P$ (Fig. 3). Based on the obtained results, a characteristic was done of the joined plates interface by the calculation (from equation 1) of the value of 'RGP' factor, so-called melt depth equivalent factor [6-8].

$$
\mathrm{RGP}=\frac{\sum_{i=1}^{n} P_{i}}{L}[\mu \mathrm{m}]
$$

where $\mathrm{P}_{\mathrm{i}}$ - surface of fusion regions in $\mu \mathrm{m}^{2}$.

L-the length of the bond line in $\mu \mathrm{m}$

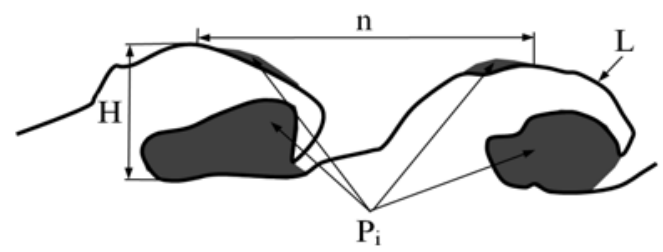

Fig. 3. Basic bond parameters: $H$-height of the wave, $\mathrm{L}$ - length of the bond line, $\mathrm{n}$-wave length, $\mathrm{P}$-'fusion' surface area.

\section{Results and discussion}

\subsection{Structural observations}

The preliminary observation of microstructure was performed by means of light microscopy. Fig 4a shows the structure of titanium sheet in as-is state i.e. before bonding in section perpendicular to lateral direction. It is evident that the material is characterized by 
the structure of compact packs of 60 to $180 \mu \mathrm{m}$ size consisting of $\alpha$ phase grains. The image (Fig.4b) presents the P355GH carbon steel microstructure in as-is state characterized by an equiaxed structure of middle-sized grains in the range of 4 to $11 \mu \mathrm{m}$ for pearlite and $10-20 \mu \mathrm{m}$ for ferrite. For pearlite, we can see a band structure of fine grains, typical for materials that underwent hot forming.

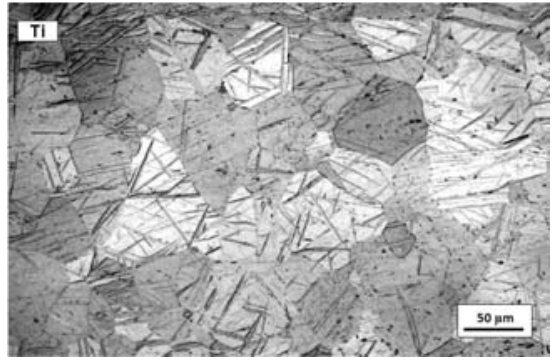

a)

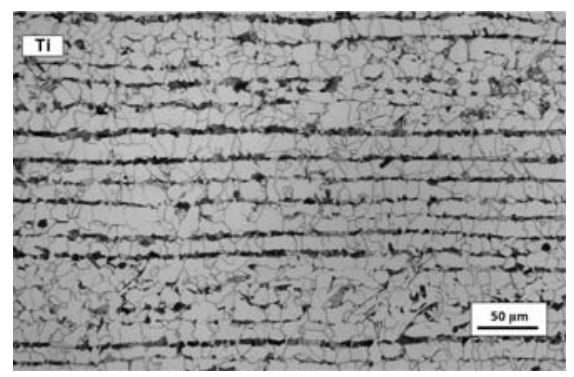

b)

Fig. 4. The initial microstructure of a) Ti Gr.1, b) steel P355GH.

The analysis of the bond zone was carried out by means of the optical microscopy on longitudinal section (in the direction of detonation front movement). Based on the performed measurements of the wave settings (Table 4) and microstructural analysis of the bond zone (Fig. 5) it can be concluded that a wavy bond was obtained in all 2 cases.

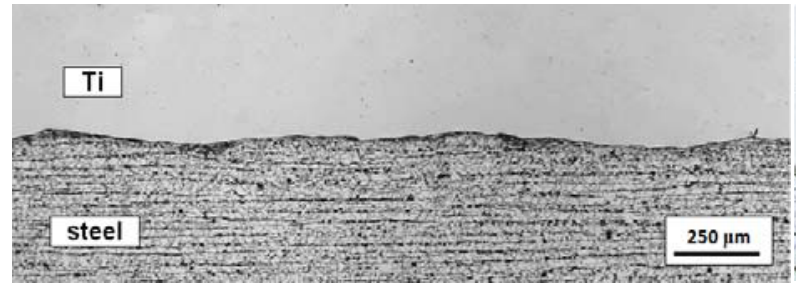

a)

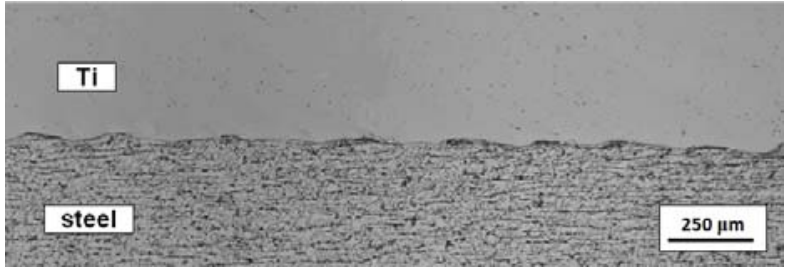

c)

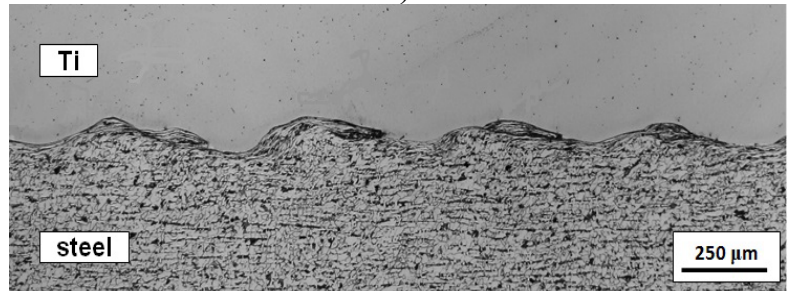

e)

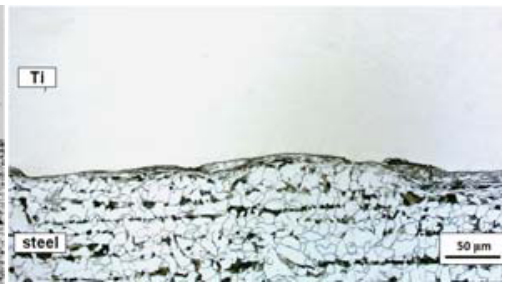

b)

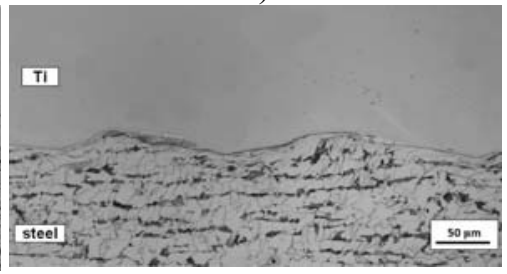

d)

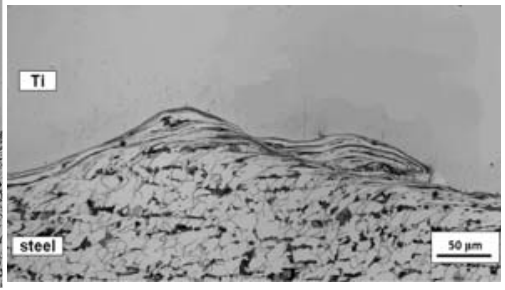

f)

Fig. 5. The influence of stand-off distance on changes near the interface: (a-b) H10, (c-d) H12, (e-f) H15. Magnification 50x (a,c,e) and 200x (b,d,f).

For all cases (H10, H12, H15) stand-off the lengths of wave $n$ was nearing (about 540 $\mu \mathrm{m}$ ). For $10 \mathrm{~mm}$ and $12 \mathrm{~mm}$ stand-off (samples H10 and H12) the height of the wave was 
$33 \mu \mathrm{m}$ and $39 \mu \mathrm{m}$ respectively, whereas for stand-off $15 \mathrm{~mm}$ (samples H15) the height of the wave was equal and reached $83 \mu \mathrm{m}$. Therefore it follows that $\mathrm{H} 12$ sample exhibited $60 \%$ increase of the height of the wave respectively as compared to H10 and H12 (Fig. 6). In the same figure we can analyse the effect of the stand-off distance between the bonded plates on the 'intensity' of the melted zone occurrence. It was noticed that the increase in the stand-off distance caused the growth of the melted area fraction in the bond, which can be established by the analysis of 'RGP' factor. Its greatest value $-1,45 \mu \mathrm{m}$ was obtained for the largest distance between the plates (sample H15). For the other two cases, it can be noticed that along with the distance decrease the 'RGP' factor goes down; for H12 and H10 $-0,71 \mu \mathrm{m}$ and $0 \mu \mathrm{m}$ respectively.

Table 4. Parameters describing wave shape and the quantity of the melted zone.

\begin{tabular}{|c|c|c|c|c|c|}
\hline Plate & $\begin{array}{c}\text { Length of the bond line } \\
\mathrm{L}[\mu \mathrm{m}]\end{array}$ & $\begin{array}{c}\text { Wave height } \\
\mathrm{H}[\mu \mathrm{m}]\end{array}$ & $\begin{array}{c}\text { Wave length } \\
\mathrm{n}[\mu \mathrm{m}]\end{array}$ & $\begin{array}{c}\text { Melt surface area } \\
\mathrm{P}\left[\mu \mathrm{m}^{2}\right]\end{array}$ & $\begin{array}{c}\text { Melt depth equivalent } \\
\mathrm{RGP}[\mu \mathrm{m}]\end{array}$ \\
\hline $\mathrm{H} 10$ & 4892 & 33 & 537 & 0 & 0 \\
\hline $\mathrm{H} 12$ & 4999 & 39 & 544 & 3558 & 0,71 \\
\hline $\mathrm{H} 15$ & 5206 & 83 & 548 & 5567 & 1,47 \\
\hline
\end{tabular}

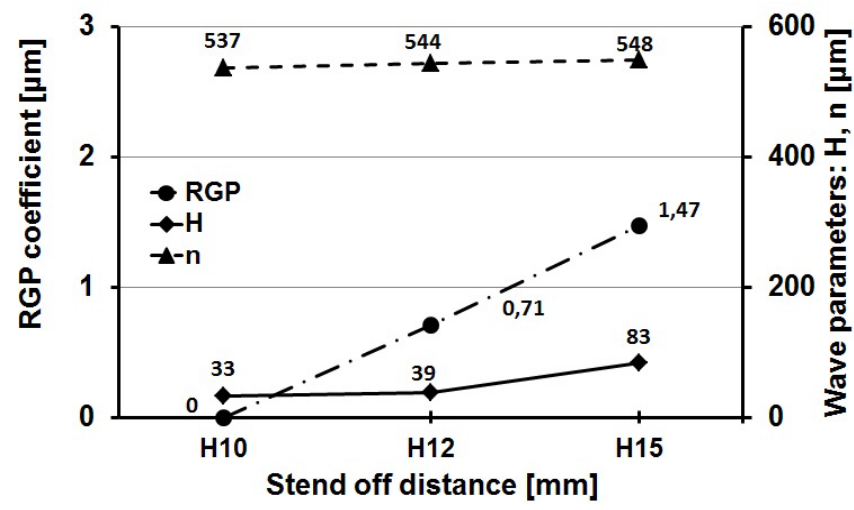

Fig. 6. Influence of the stand-off distance near the interface.

On the basis of the performed observations and measurements it can be concluded that the distance between the plates strongly influences bond-defining parameters. It is noticeable particularly when analysing the fraction of melted layers at the bond interface. Namely, with the same explosion energy, the decrease of the distance leads to a considerable reduction of the melted area.

\subsection{Mechanical tests}

In case of bending tests, best result was obtained for biggest stand-off distance (specimen H15), which achieved full bend (180 degrees) without any delaminating. In case of other specimens, were delaminated for bend to $40^{\circ}$ for specimen $\mathrm{H} 10$ and to $90^{\circ}$ for specimen H12.

The qualitative assessment of the obtained bond was performed based on mechanical properties determined by means of shearing tests, lateral bending and ram tests. The average values resulting from individual strength tests were presented in Fig. 7. For shearing tests, in all analysed cases, the results exceeded more than twice the minimum standard threshold of $\mathrm{R}_{\mathrm{s}}=140 \mathrm{MPa}$. The highest $\mathrm{R}_{\mathrm{s}}$ values of about $520 \mathrm{MPa}$ were recorded for narrow distances between the plates (H10). Larger distances added to decreasing the shear strength, which was $472 \mathrm{MPa}$ and $417 \mathrm{MPa}$ for H12 and H15 samples, respectively. 
During the ram test the value of $\mathrm{R}_{\mathrm{o}}$ was noticed to increase along with the decrease of the stand-off distance.

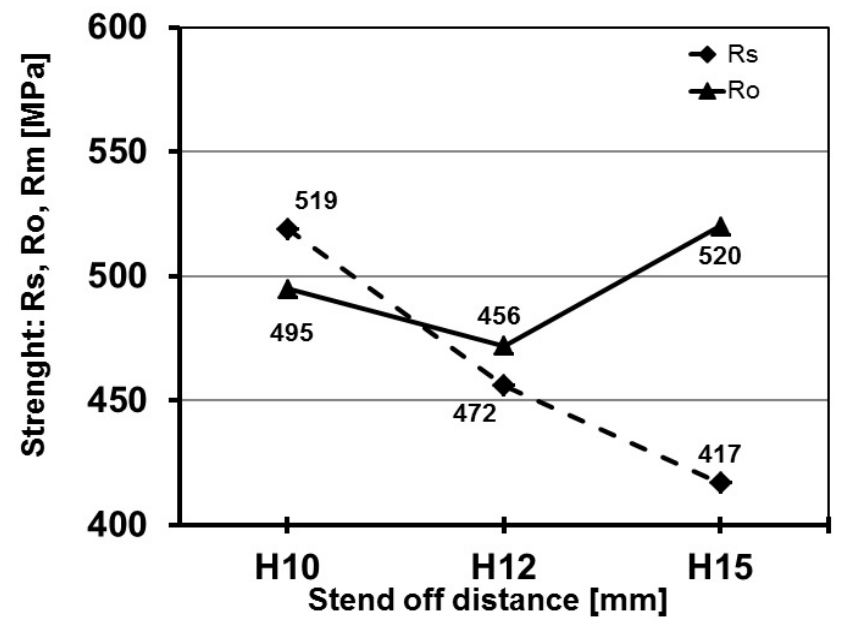

Fig. 7. The mechanical properties of Ti/P355GH bimetals.

The highest $\mathrm{R}_{\mathrm{o}}$ values of $520 \mathrm{MPa}$ was obtained for specimen cut out from plates welded with the greatest distance between the sheets (H15), Fig 7. For A8 (2h) specimens a $5 \%$ decrease of ram strength was recorded. In the case of bimetals fabricated with a small distance between the plates (H10 and H12) a 5-15\% drop of $\mathrm{R}_{0}$ compared to the maximum result was observed. The lower quality of the weld is also confirmed by the fact that every specimens were destroyed at the bond.

\subsection{Microhardness measurements}

The analysis of the microhardness distribution on the section's surface revealed a considerable increase of the hardening both in the base material as well as the cladding metal compared to the initial state material hardness. Close to the bond zone in the steel and Ti plates, a $25-35 \%$ improvement of hardness was noticed, which was approximately equal to all the analysed arrangements (Fig. 8a).

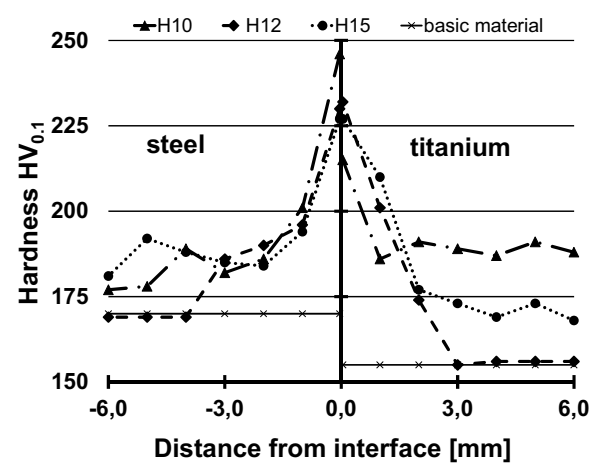

a)

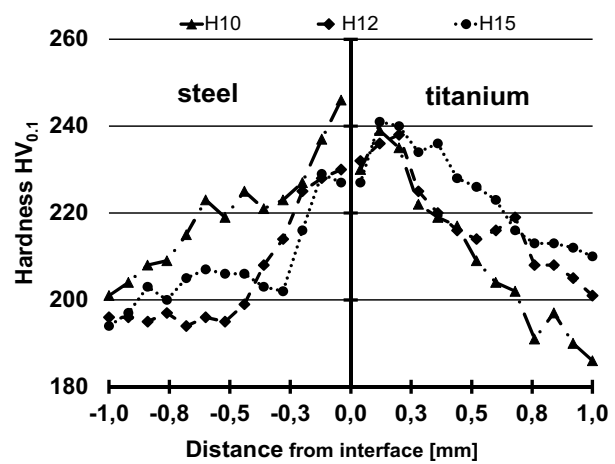

b)

Fig. 8. Microhardness measurements along 3 'scan' lines across the interface, for all analysed cases (up to $0,5 \mathrm{~mm}$ from the interface). Load $50 \mathrm{G}$.

A more detailed distribution of microhardness was analysed at the distance of $1 \mathrm{~mm}$ from the bond interface (Fig. 8b). The analysis of the obtained results confirms that the 
greatest hardening is displayed by the plate fabricated with the smaller stand-off distance between the plates, i.e. H10 and H12 samples, whereas the smallest was displayed by H15 sample. The graph shows an undeniable influence of the stand-off distance on the hardening improvement of steel. In particular, it was observed that changing the stand-off distance contributes to hardening improvement on the side of steel, but this tendency was not noticed for titanium.

\section{Conclusions}

The present study analyses the effect of the stand-off distance between the joined plates during explosion welding on the properties of the Ti/P355GH clad. The performed research allowed the formation of the following conclusions:

1. The mechanical properties of the fabricated bimetals, shear strength $\mathrm{R}_{\mathrm{S}}$ strongly depend on the stand-off distance between the plates; their values rise with extending the distance.

2. Characteristic bond zone parameters, in particular the amount of melt in the bond are determined by the initial stand-off distance of the joined plates; extending the distance causes decreasing of the 'RGP' factor, i.e. the reduction of the melt volume in the bond zone occurs.

3. As a result of explosion welding, hardening of the joined materials occurs near the interface. Nevertheless, it is more pronounced in steel and less in Ti. The volume of the hardened area heavily depends on the stand-off distance. The greatest hardening, both in the steel and Ti plates, occurs in the areas adjacent to the boundary.

\section{References}

1. G. Jutjering, J.C. Williams, Titanium. Engineering Materials and Processes (Springer, Heidelberg, 2007)

2. P. Nieslony, P. Cichosz, G.M. Krolczyk, S. Legutko, D. Smyczek, M. Kolodziej, Measurement 78, 129 (2016)

3. P. Nieslony, G.M. Krolczyk, K. Zak, R.W. Maruda, S. Legutko, Precis. Eng. (to be published)

4. T.Z. Blazynski (ed.), Explosive welding, forming and compaction, (Applied Science Publishers, London and New York 1983)

5. F. Findik, Mater. Design 32, 1081(2011)

6. M. Prazmowski, H. Paul, J. Morgiel, Metal Forming XXV, 257 (2014)

7. H. Paul, M. Faryna, M. Prażmowski, R. Bański, Arch. Metall. Mater. 56, 463 (2011)

8. H. Paul, L. Lityńska-Dobrzyńska, M. Prażmowski, Arch. Metall. Mater. 57, 1151 (2012)

9. A. Nobili, Nobelclad Technical Bulletin Nt, Nobelclad, Rivesaltes, France (2002)

10. ISD Trade Sp. z o.o., Inspection certificate, PN-EN 10204/06-3.1

11. BAOIJ Titanium Industry Co. LTD, Material certification, EN 10204 3.2. 